Check for updates

Cite this: J. Mater. Chem. A, 2017, 5 , 20381

Received 3rd May 2017

Accepted 1st September 2017

DOI: $10.1039 / \mathrm{c} 7 \mathrm{ta0} 03802 \mathrm{j}$

rsc.li/materials-a

\section{Room temperature nanoparticulate interfacial layers for perovskite solar cells via solvothermal synthesis $\uparrow$}

\author{
Achilleas Savva, ${ }^{a}$ Ioannis T. Papadas, ${ }^{a}$ Dimitris Tsikritzis, ${ }^{a}$ Gerasimos S. Armatas, (D) b \\ Stella Kennou ${ }^{c}$ and Stelios A. Choulis (D) *a
}

\begin{abstract}
We present a solvothermal synthetic route to produce monodisperse CuO nanoparticles (NPs) in the range of 5-10 $\mathrm{nm}$ that can be used as a hole selective interfacial layer between indium tin oxide (ITO) and the perovskite active layer for $\mathrm{p}-\mathrm{i}-\mathrm{n}$ perovskite solar cells by spin casting the dispersions at room temperature. The bottom electrode interface modification provided by spherical CuO-NPs at room temperature promotes the formation of high quality perovskite photoactive layers with a large crystal size and strong optical absorption. Furthermore, it is shown that the nanoparticulate nature of the $\mathrm{CuO}$ hole transporting interfacial layer can be used to improve light manipulation within the perovskite solar cell device structure. The corresponding $\mathrm{p}-\mathrm{i}-\mathrm{n} \mathrm{CH}_{3} \mathrm{NH}_{3} \mathrm{Pbl}_{3}$-based solar cells show high $V_{\text {oc }}$ values of $1.09 \mathrm{~V}$, which is significantly higher compared to the $V_{\text {oc }}$ values obtained with conventional PEDOT:PSS hole selective contact based perovskite solar cells.
\end{abstract}

\section{Introduction}

Organic-inorganic lead halide perovskites have been identified as key materials for many optoelectronic applications. ${ }^{\mathbf{1 , 2}}$ Perovskite-based solar cells have demonstrated power conversion efficiencies (PCEs) above $20 \%{ }^{3,4}$ within only a few years of development. ${ }^{5}$ Solid-state perovskite solar cells have been triggered by the pioneering work of H.-S. Kim et al. ${ }^{6}$ Since then, perovskite solar cell device engineering has made substantial improvement towards facile, innovative concepts. Planar heterojunction $(\mathrm{PHJ})$ perovskite-based solar cells processed by costeffective solution routes highlight their great merit for future commercialization. $^{7}$

Inverted $\mathrm{p}-\mathrm{i}-\mathrm{n}$ perovskite solar cells have recently attracted increased interest ${ }^{8}$ due to the low-cost and easy processing of charge selective contacts that can be used in this device structure. Importantly within the $\mathrm{p}-\mathrm{i}-\mathrm{n}$ perovskite the utilization of high cost hole transporting layers like Spiro-MeOTAD as well as high temperature processed n-type materials like $\mathrm{TiO}_{2}$ at $500{ }^{\circ} \mathrm{C}$ can be avoided. In addition, the fullerene based interfacial layer processed on top of the perovskite as an n-type contact has been

\footnotetext{
${ }^{a}$ Molecular Electronics and Photonics Research Unit, Department of Mechanical Engineering and Materials Science and Engineering, Cyprus University of Technology, Limassol, 3603, Cyprus. E-mail: stelios.choulis@cut.ac.cy

${ }^{b}$ Department of Materials Science and Technology, University of Crete, Heraklion 71003, Greece

${ }^{c}$ Department of Chemical Engineering, University of Patras, Patra, 26504 Greece

† Electronic supplementary information (ESI) available. See DOI: $10.1039 / \mathrm{c} 7 \mathrm{ta} 03802 \mathrm{j}$
}

found to reduce the current-voltage $(J-V)$ curve hysteresis which is generally observed in $\mathrm{n}-\mathrm{i}-\mathrm{p}$ structures when applying different scan directions. ${ }^{9}$

In principle, the corresponding bandgap $\left(E_{\mathrm{g}}\right)$ of the photoactive material determines the upper limit of the achievable open-circuit voltage $\left(V_{\mathrm{oc}}\right)$ in planar heterojunction $(\mathrm{PHJ})$ perovskite solar cells. According to the Shockley-Queisser theory, ${ }^{\mathbf{1 0}}$ there are intrinsically thermodynamic constraints for materials that eventually result in a minimum voltage loss of about 250$300 \mathrm{mV}$. Moreover, charge recombination within the photoactive material and energetic charge barriers in the stratified devices may also contribute to an additional voltage loss, further reducing the resultant $V_{\text {oc }}$ of the device. ${ }^{11}$ Importantly, perovskite solar cells show the potential for achieving low voltage loss $(<0.5 \mathrm{~V}) .{ }^{12}$ Therefore, it is critical to pursue material systems with minimal voltage loss for developing highperformance solar cell devices.

Poly(3,4-ethylenedioxythiophene):polystyrene sulfonate (PEDOT:PSS) is a widely used p-type material for optoelectronic applications $^{\mathbf{1 3}}$ and the most commonly used hole selective contact in $\mathrm{p}-\mathrm{i}-\mathrm{n}$ perovskite solar cells. However, despite its excellent properties, most of the PEDOT:PSS-based $\mathrm{CH}_{3} \mathrm{NH}_{3}$ $\mathrm{PbI}_{3}$ solar cells reported to date suffered from an inferior opencircuit voltage $\left(V_{\text {oc }} \sim 0.88-0.97 \mathrm{~V}\right)$ compared with that obtained for conventional $\mathrm{CH}_{3} \mathrm{NH}_{3} \mathrm{PbI}_{3}$-based solar cells (1.05-1.12 V). ${ }^{14}$ It is generally believed that the lower $V_{\mathrm{oc}}$ originates from the mismatched energy level alignment between the work function of PEDOT:PSS (4.9-5.2 eV) ${ }^{15}$ and the valence band maximum (5.4 eV) of $\mathrm{CH}_{3} \mathrm{NH}_{3} \mathrm{PbI}_{3}$. Furthermore, it is observed that the perovskite photoactive layers, which are formed on top of the 
PEDOT:PSS, exhibit relatively small grain sizes that significantly deteriorate the overall device performance.

In general, it is proved that the under-layers have a significant influence on the grain size of the perovskite photoactive layers which are formed on top. ${ }^{16}$ Polymeric p-type materials, like poly[bis(4-phenyl)(2,4,6-trimethylphenyl)amine] (PTAA), have been reported to be efficient hole selective contacts, leading to larger perovskite grain sizes compared with those formed on top of PEDOT:PSS. In addition, the higher work function of these materials results in enhanced bottom electrode selectivity and, thus, the formation of perovskite solar cells with higher $V_{\mathrm{oc}}$. Nevertheless, the high cost of these materials due to their complicated synthetic procedure and high-purity requirement immensely hamper the future commercialization of perovskite solar cells.

For further cost-effective application, low-cost, simply prepared and stable inorganic hole conductors have been identified as promising alternatives to the costly organic hole conductors and low performing PEDOT:PSS. Solution processed $\mathrm{NiO},{ }^{17} \mathrm{CuNiO}_{x},{ }^{18}$ and $\mathrm{CuSCN}^{19}$ materials have been reported to be efficient hole selective contacts, which result in high $V_{\text {oc }}$ values $(>1 \mathrm{~V})$ and increased $\mathrm{p}-\mathrm{i}-\mathrm{n}$ device performance compared with PEDOT:PSS-based perovskite solar cells.

Typically, to form functional solution processed metal oxides as hole-transport layers (HTLs) for $\mathrm{p}-\mathrm{i}-\mathrm{n}$ perovskite solar cells, modified sol-gel methods are used. These methods usually require coating of a precursor metal salt solution and then a post-annealing treatment in order to achieve high quality, electrically active metal oxide thin films. ${ }^{20}$ The high temperature processing steps involved in this process, however, are not compatible with the flexible perovskite solar technology targets. ${ }^{21} \mathrm{~A}$ second approach for fabricating metal oxide based HTLs for $\mathrm{p}-\mathrm{i}-\mathrm{n}$ perovskite solar cells is the synthesis of high crystallinity and high purity nanoparticle (NP) dispersions. ${ }^{22,23}$ The dispersions are processed using plain solution processing followed by post deposition treatments to remove excess organic residuals and to promote film functionality. ${ }^{24}$ It has been reported that this approach could provide more flexibility in processing by avoiding prolonged post deposition treatments. ${ }^{25}$

For efficient planar perovskite solar cell application, the compactness of the inorganic nanoparticulate under-layers is of high importance. ${ }^{26}$ To achieve this, it is crucial for the synthesized NPs to have a small size and narrow distribution of the particle sizes. ${ }^{27}$ A typical problem of the existing synthetic routes is that the as-prepared NPs are severely agglomerated, thus making it difficult to control the size and shape of the particles. In addition, in most of the cases these methods require the usage of toxic and expensive reagents or proceed at high temperature and through complex synthetic routes.

$\mathrm{CuO}$ is a low-cost material which has been used in various applications, such as catalysis, ${ }^{28}$ water splitting photocatalysis $^{29,30}$ and gas sensing. ${ }^{31} \mathrm{CuO}$ is a promising $\mathrm{HTL}$ for perovskite solar cells. ${ }^{32}$ Recent studies demonstrate $\mathrm{CuO}_{x}$-based HTLs starting from metal salt precursors ${ }^{33,34}$ and the $\mathrm{Cu}(\mathrm{acac})_{2}$ compound in $o$-DCB solution..$^{35}$ All the reported $\mathrm{CuO}_{x}$-HTLs require thermal-annealing steps combined in some cases with additional solvent washing steps to ensure HTL functionality.

In this study, we demonstrate a new strategy for fabricating nanoparticulate interfacial layers for $\mathrm{p}-\mathrm{i}-\mathrm{n}$ perovskite solar cells based on copper(II) oxide NP dispersions. Importantly for printed electronic applications the proposed synthetic route can be used to develop functional CuO HTLs at room temperature eliminating the requirement of the annealing step during the fabrication process. Furthermore, we show that the proposed nanoparticulate based interface modification concept can be used to improve light manipulation providing in parallel a series of other benefits in $\mathrm{p}-\mathrm{i}-\mathrm{n}$ perovskite solar cell device operation. The cupric oxide (CuO) NPs are synthesized from $\mathrm{CuCl}$ thermal decomposition in DMSO at low temperature $\left(80-120^{\circ} \mathrm{C}\right)$ and within a short reaction time (30 minutes). As proved by XRD, TEM and EDS measurements, the CuO NPs are of high purity with a monoclinic crystal structure, spherical in shape and with a tunable diameter (from 5 to $10 \mathrm{~nm}$ ) depending on the reaction conditions. Stable dispersions of the CuO NPs in DMSO were used to fabricate interfacial layers of $\mathrm{CuO}$ without any post deposition annealing or solvent washing step in the range of $\sim 15 \mathrm{~nm}$. The room temperature solution processed $\mathrm{CuO}$ interfacial layers exhibit a high work function, transparency and good surface properties to facilitate high quality perovskite photoactive layers on top of them with significantly increased grain size compared with PEDOT:PSS. It is proved that the use of CuO NPs as interfacial layers between ITO and $\mathrm{CH}_{3} \mathrm{NH}_{3} \mathrm{PbI}_{3}$ leads to good photovoltaic operation with a maximum PCE of $15.3 \%$, high $V_{\text {oc }}$ values of $1.09 \mathrm{~V}$ and over $50 \%$ increase in PCE compared with PEDOT:PSS-based p-i-n perovskite-based solar cells. The devices under study are analyzed using electro-optical characterization, suggesting that the nanoparticulate nature of the $\mathrm{CuO}$ interfacial layer leads to light management benefits for the photovoltaic device performance of the $\mathrm{p}-\mathrm{i}-\mathrm{n}$ perovskite solar cells.

\section{Experimental}

\section{Materials}

Pre-patterned glass-ITO substrates (sheet resistance $4 \Omega \mathrm{sq}^{-1}$ ) were purchased from Psiotec Ltd, $\mathrm{PbI}_{2}$ from Alfa Aesar, MAI from Dyenamo Ltd, aluminum-doped zinc oxide (AZO) ink from Nanograde (product no. N-20X), PC[70]BM from Solenne BV and PEDOT:PSS from H. C. Starck (Clevios P VP Al 4083). All the other chemicals used in this study were purchased from Sigma Aldrich.

\section{Synthesis of CuO NPs}

2 moles of copper chloride were added into $10 \mathrm{~mL}$ of dimethyl sulfoxide (DMSO). The solution was heated at various temperatures and for the desired reaction time while constantly stirring it at a high rate, thus forming a homogeneous solution. The formation of CuO NPs was indicated by the color change of the precursor solution to black. To clean the CuO NPs from impurities and to improve the quality of the dispersions, we used the following procedure: the $\mathrm{CuO}$ NPs were isolated by 
centrifugation, washed with DMSO/toluene (2:1 v/v) twice, and re-dispersed in DMSO. Three series of CuO NPs were synthesized under the scope of this study by changing only the decomposition temperature, i.e. $\mathrm{CuO}-20 \mathrm{mg} \mathrm{mL}^{-1}-120{ }^{\circ} \mathrm{C}-30$ minutes, $\mathrm{CuO}-20 \mathrm{mg} \mathrm{mL} \mathrm{m}^{-1}-100{ }^{\circ} \mathrm{C}-30$ minutes and $\mathrm{CuO}-20 \mathrm{mg} \mathrm{mL}^{-1}$ $80{ }^{\circ} \mathrm{C}-30$ minutes. We also found that the size of NPs can be increased by using longer reaction times or more concentrated precursor solutions (data not shown).

\section{Device fabrication}

The $\mathrm{p}-\mathrm{i}-\mathrm{n}$ solar cells under comparison were ITO/PEDOT:PSS or CuO-NPs/CH $\mathrm{CH}_{3} \mathrm{NH}_{3} \mathrm{PbI}_{3} / \mathrm{PC}[70] \mathrm{BM} / \mathrm{AZO} / \mathrm{Al}$. ITO substrates were sonicated in acetone and subsequently in isopropanol for 10 minutes and heated at $120{ }^{\circ} \mathrm{C}$ on a hot plate 10 minutes before use. To form a $40 \mathrm{~nm}$ hole transporting layer, the PEDOT:PSS ink was dynamically spin coated at $6000 \mathrm{rpm}$ for $30 \mathrm{~s}$ in air on the preheated ITO substrates and then transferred into a nitrogen filled glovebox for 25 minute annealing at $120{ }^{\circ} \mathrm{C}$. To form an $\sim 15 \mathrm{~nm}$ CuO nanoparticulate thin film, the as prepared dispersions were diluted to $0.5 \mathrm{mg} \mathrm{mL}^{-1}$ in DMSO and dynamically spin coated at $6 \mathrm{k}$ rpm followed by a methanol washing step at $3 \mathrm{k}-30$ s-30 $\mu \mathrm{L}$. The perovskite solution was prepared 30 minutes prior to spin coating by mixing $\mathrm{PbI}_{2}$ : methylammonium iodide $(1: 3)$ at $46 \%$ wt in DMF with the addition of $1.5 \mathrm{~mol} \%$ of methylammonium bromide (to $\mathrm{PbI}_{2}$ ). The precursor was filtered with $0.1 \mu \mathrm{m}$ PTFE filters. The perovskite precursor solution was deposited on the HTLs by static spin coating at $4 \mathrm{k} \mathrm{rpm}$ for 60 seconds and annealing for 5 minutes at $80{ }^{\circ} \mathrm{C}$, resulting in a film with a thickness of $\sim 200 \mathrm{~nm}$. The PC[70]BM solution, $20 \mathrm{mg} \mathrm{mL}^{-1}$ in chlorobenzene, was dynamically spin coated on the perovskite layer at $1 \mathrm{k} \mathrm{rpm}$ for $30 \mathrm{~s}$. AZO ink was dynamically spin coated on top of $\mathrm{PC}[70] \mathrm{BM}$ at $3 \mathrm{k} \mathrm{rpm}$ for $30 \mathrm{~s}$ to fabricate $\sim 30 \mathrm{~nm}$ thin films. Finally, $100 \mathrm{~nm} \mathrm{Al} \mathrm{layers} \mathrm{were} \mathrm{thermally} \mathrm{evaporated} \mathrm{through}$ a shadow mask to finalize the devices. Encapsulation was applied directly after evaporation in the glovebox using a glass coverslip and an Ossila E131 encapsulation epoxy resin activated by $365 \mathrm{~nm}$ UV-irradiation. The active area of the devices was $0.09 \mathrm{~mm}^{2}$.

\section{Characterization}

The thicknesses of the active layers were measured with a Veeco Dektak 150 profilometer. The current density-voltage $(J / V)$ characteristics were investigated with a Botest LIV Functionality Test System. Both forward (short circuit $\rightarrow$ open circuit) and reverse (open circuit $\rightarrow$ short circuit) scans were measured with $10 \mathrm{mV}$ voltage steps and $40 \mathrm{~ms}$ of delay time. For illumination, a calibrated Newport Solar simulator equipped with a Xe lamp was used, providing an AM1.5G spectrum at $100 \mathrm{~mW} \mathrm{~cm} \mathrm{~cm}^{-2}$ as measured by a certified oriel $91150 \mathrm{~V}$ calibration cell. A custommade shadow mask was attached to each device prior to measurements to accurately define the corresponding device area. Optical absorption measurements were performed using a Shimadzu UV-2700 UV-Vis spectrophotometer. Diffuse reflectance was recorded at room temperature, using powder $\mathrm{BaSO}_{4}$ as a $100 \%$ reflectance standard. Reflectance data were converted to absorption $(\alpha / S)$ according to the Kubelka-Munk equation: $\alpha /$ $S=(1-R)^{2} /(2 R)$, where $R$ is the reflectance and $\alpha$ and $S$ are the absorption and scattering coefficients, respectively. Steady-state PL experiments were performed on a Fluorolog-3 Horiba Jobin Yvon spectrometer based on an iHR320 monochromator equipped with a visible photomultiplier tube (Horiba TBX-04 module). The PL was non-resonantly excited at $400 \mathrm{~nm}$ with the line of a $5 \mathrm{~mW}$ Oxxius laser diode. Contact angle measurements were performed using a KRUSS DSA100E drop shape analysis system. The value of the water contact angle was calculated using the EasyDrop software, using the sessile drop method. For the surface energy measurements, the contact angles of 3 known surface tension liquids were measured on top of the surfaces under study. The polar and dispersive parts of the surface tension of the liquids were calculated via the pendant drop method. Atomic force microscopy (AFM) images were obtained using a Nanosurf easy scan 2 controller in the tapping mode. X-ray diffraction (XRD) patterns were collected on a PANalytical X'pert Pro MPD powder diffractometer $(40 \mathrm{kV}$, $45 \mathrm{~mA})$ using $\mathrm{Cu} \mathrm{K} \alpha$ radiation $(\lambda=1.5418 \AA)$. Transmission electron microscope (TEM) images and electron diffraction patterns were recorded on a JEOL JEM-2100 microscope with an acceleration voltage of $200 \mathrm{kV}$. The samples were first gently ground, suspended in ethanol and then picked up on a carboncoated $\mathrm{Cu}$ grid. Quantitative microprobe analysis was performed on a JEOL JSM-6390LV scanning electron microscope (SEM) equipped with an Oxford INCA PentaFET-x3 energy dispersive X-ray spectroscopy (EDS) detector. Data acquisition was performed with an accelerating voltage of $20 \mathrm{kV}$ and $60 \mathrm{~s}$ accumulation time. X-ray photoelectron spectra (XPS) and Ultraviolet Photoelectron Spectra (UPS) were recorded by using a Leybold EA-11 electron analyzer operating in constant energy mode at a pass energy of $100 \mathrm{eV}$ and at a constant retard ratio of $4 \mathrm{eV}$ for XPS and UPS, respectively. The spectrometer energy scale was calibrated by the $\mathrm{Au} 4 \mathrm{f}_{7 / 2}$ core level binding energy, $\mathrm{BE},(84.0 \pm 0.1 \mathrm{eV})$ and the energy scale of the UPS measurements was referenced to the Fermi level position of $\mathrm{Au}$ at a binding energy of $0 \mathrm{eV}$. All binding energies were referred to the $\mathrm{C}$ 1s peak at $284.8 \mathrm{eV}$ of surface adventitious carbon. The $\mathrm{X}$-ray source for all measurements was a non-monochromatized $\mathrm{Al} \mathrm{K} \alpha$ line at $1486.6 \mathrm{eV}$ (12 keV with $20 \mathrm{~mA}$ anode current). For UPS measurements, the He I (21.22 eV) excitation line was used. A negative bias of $12.22 \mathrm{~V}$ was applied to the samples during UPS measurements in order to separate secondary electrons originating from the sample and the spectrometer. The analyzer resolution was determined from the width of the Au Fermi edge to be $0.16 \mathrm{eV}$. The sample work function was determined by subtracting the high binding energy cut-off from the He I excitation energy ( $21.22 \mathrm{eV})$. The position of the high-energy cut-off was determined by the intersection of a linear fit of the high binding portion of the spectrum with the background. Similarly, the valence band maximum is determined with respect to the Fermi level, from the linear extrapolation of the valence band edge to the background.

\section{Results and discussion}

The CuO NPs were synthesized using a simple synthetic procedure at low temperature as described in detail within the 
Experimental section. The thermal decomposition of $\mathrm{CuCl}$ in DMSO was proven as an uncomplicated way to tune the particle size by simply changing the reaction temperature from 80 to $120^{\circ} \mathrm{C}$. In this procedure, DMSO acts as ancillary ligand to form complexes with the metal halide precursor in a way that solvent molecules replace $\mathrm{Cl}^{-}$in $\mathrm{CuCl}$ through a bridge-splitting reaction, producing monodisperse NPs of $\mathrm{CuO}$ during the thermal decomposition synthesis. Fig. 1 shows XRD and TEM data which accurately illustrate the crystal phase, shape and size of the as-obtained CuO NPs. The initial concentration of the $\mathrm{CuCl}$ solution was $20 \mathrm{mg} \mathrm{mL}^{-1}$ and the reaction time was $30 \mathrm{~min}$ in all experiments.

Fig. 1a shows the XRD patterns of the CuO NPs prepared at three different reaction temperatures, i.e. 80, 100 and $120^{\circ} \mathrm{C}$; all the XRD peaks can be assigned to the monoclinic structure of CuO with lattice constants of $a=0.4688 \mathrm{~nm}, b=0.3423 \mathrm{~nm}, c=$ $0.5129 \mathrm{~nm}$ and $\beta=99.506^{\circ}$ (JCPDS card no. $48-1548$ ). No peaks of impurities were observed in the XRD patterns, indicating the high phase purity of the CuO. The latter is also verified by EDS analysis in which very low impurities of $\mathrm{Cl}$ have been detected (less than $2 \%$ by weight, ESI Fig. S1 $\dagger$ ). The crystal structure of the CuO NPs was further studied by selected-area electron diffraction (SAED). The SAED pattern in Fig. 1b, taken from a small area of the NP aggregates (as formed by the TEM preparation of the sample), corroborates the crystallinity observed in XRD patterns. It shows a series of Debye-Scherrer diffraction rings, which can be well indexed to monoclinic $\mathrm{CuO}$ (space group: $C 2 / c$, tenorite). The average size of the CuO NPs was estimated from the (111) diffraction peak by using the Scherrer formula, and it was found to be $\sim 5.7 \mathrm{~nm}$ for $80^{\circ} \mathrm{C}$, $\sim 6.3 \mathrm{~nm}$ for $100{ }^{\circ} \mathrm{C}$ and $\sim 10 \mathrm{~nm}$ for $120{ }^{\circ} \mathrm{C}$ reaction temperature. Fig. 1c and d show the typical TEM images of the CuO NPs prepared at $100{ }^{\circ} \mathrm{C}$. These images clearly show spherical NPs with an average size of $5.9 \pm 0.7 \mathrm{~nm}$ (inset of Fig. 1c), consistent with XRD results. Note that the average diameter of the $\mathrm{CuO}$ NPs was estimated by counting more than 100 individual NPs in several TEM images (Fig. S2 $\dagger$ ). The high resolution TEM (HRTEM) image, in Fig. 1d (inset), shows lattice fringes of a CuO NP, suggesting a well-defined crystal structure. The lattice fringes with a $d$-spacing of $2.5 \AA$ are assigned to the (002) planes of the $\mathrm{CuO}$ phase with a monoclinic structure. Finally, to investigate the electronic structure of the synthesized CuO NPs, diffuse reflectance UV-Vis-near-IR spectroscopy was used. Fig. $\mathrm{S} 3 \uparrow$ represents the Tauc plots for direct band gap transitions, from which the optical energy gap was estimated to be $1.45,1.43$ and $1.38 \mathrm{eV}$ for $\mathrm{CuO}$ NPs prepared at 80, 100 and $120{ }^{\circ} \mathrm{C}$, respectively.

To fabricate compact CuO NP thin films, stable dispersions in appropriate solvents are of high importance. All the CuO NPs produced at different temperatures were well dispersed in DMSO without the use of any dispersive agents (Fig. S4 $\dagger$ ). Sulfoxides, such as DMSO, are proposed to serve as a ligand for binding to the CuO NP surface and thus play a crucial role in stabilizing $\mathrm{CuO}$ NPs and promoting the monodispersity of
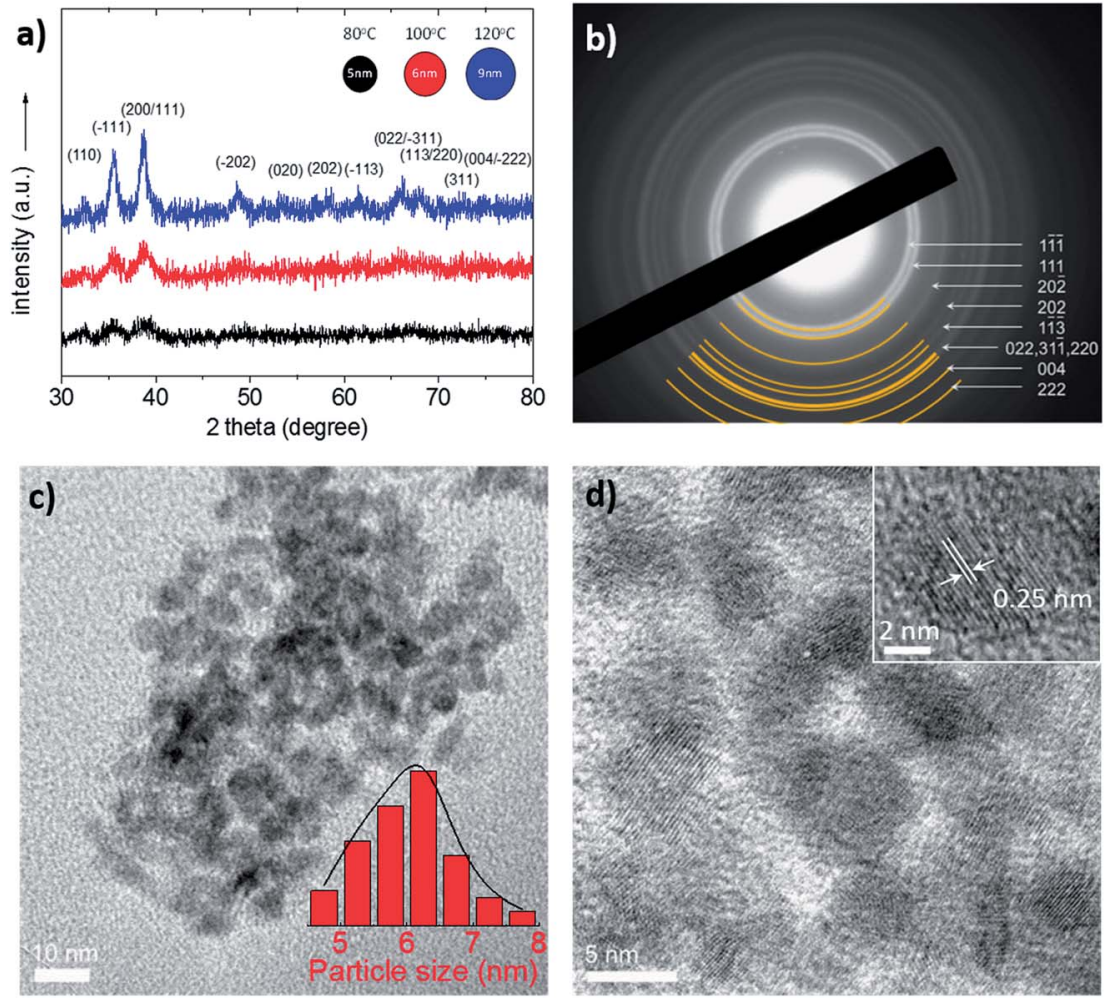

Fig. 1 (a) XRD patterns of CuO NPs obtained at $80^{\circ} \mathrm{C}$ (black), $100^{\circ} \mathrm{C}$ (red) and $120^{\circ} \mathrm{C}$ (blue line) decomposition temperatures. (b) SAED pattern and (c and d) representative TEM images of CUO NPs obtained at $100^{\circ} \mathrm{C}$ decomposition temperature. The inset in panel (c) displays the histogram of the size distribution of CuO NPs, showing an average particle diameter of $5.9 \pm 0.7 \mathrm{~nm}$. The inset in panel (d) displays the high-resolution TEM (HRTEM) image of an individual CuO NP annealed at $100^{\circ} \mathrm{C}$. 
nanocrystals. Characterization of the coordination properties of DMSO in these reactions, however, is complicated and insights thus far have been limited to computational studies. The asprepared $\mathrm{CuO}$ NPs with an initial concentration of $20 \mathrm{mg}$ $\mathrm{mL}^{-1}$ were further diluted down to $0.5 \mathrm{mg} \mathrm{mL}^{-1}$ for the fabrication of homogeneous layers with $15 \mathrm{~nm}$ thickness. As shown in the AFM image in Fig. S5, $\uparrow$ compact thin films of CuO NPs can be fabricated by simple spin coating of the dispersions without any post deposition treatment. However, it is observed that the NP size has a great influence on the resulting thin film properties. In particular, compact ultrathin films necessary for good photovoltaic operation are not able to be produced by using CuO NPs synthesized at $120{ }^{\circ} \mathrm{C}$ (average particle size $\sim 9$ $\mathrm{nm}$ ). In addition, despite that compact thin films in the range of $\sim 15 \mathrm{~nm}$ can be obtained from CuO NPs synthesized at $80{ }^{\circ} \mathrm{C}$ (average particle size $\sim 5 \mathrm{~nm}$ ), we observe significantly lower PCEs for the corresponding devices (Fig. S6†). The CuO NPs prepared at $100{ }^{\circ} \mathrm{C}$ (average particle size $\sim 6 \mathrm{~nm}$ ) were found to lead to higher PCEs compared with the other CuO samples and are extensively analyzed in the rest of the paper.

As previously mentioned the electronic and surface properties of the bottom electrode are crucial for device operation and the formation of perovskite photoactive layers. Fig. 2 shows the XPS/UPS studies, optical absorption spectra and surface wetting envelopes of ITO/CuO NP (prepared at $100{ }^{\circ} \mathrm{C}$ ) films.

Fig. 2a shows the XPS $\mathrm{Cu} 2 \mathrm{p}$ peak. The $\mathrm{Cu} 2 \mathrm{p}_{3 / 2}$ peak is located at $933.9 \mathrm{eV}$ and is accompanied by a broad satellite on the high binding energy side at about 9-10 eV. Both the binding energy of $\mathrm{Cu} 2 \mathrm{p}_{3 / 2}$ and the fine structure of the satellite are characteristic of $\mathrm{CuO}$ and are in agreement with the literature. ${ }^{36,37}$ This is experimental evidence that high quality $\mathrm{CuO}$ layers are formed on top of ITO without any annealing treatment.

Fig. $2 \mathrm{~b}$ shows the UPS spectrum of the $\mathrm{CuO} / \mathrm{ITO}$ interface. The work function of the $\mathrm{CuO}$ was determined to be $5.4 \mathrm{eV}$ from the high binding energy cut-off as is described in the Experimental section. The valence band region near the Fermi level shows broad features between 2 and $7 \mathrm{eV}$ originating from overlapping $\mathrm{Cu} 3 \mathrm{~d}$ and $\mathrm{O} 2 \mathrm{p}$ levels. ${ }^{38}$ The metallic nature of $\mathrm{CuO}$ is confirmed by the occupied states very close to the Fermi level and the valence band maximum was determined to be $0.3 \mathrm{eV}$ below the Fermi level. CuO has d-bands partially occupied with a high number of electrons and the valence band maximum is reported to be $0.1 \mathrm{eV}$ below the Fermi level, but when the oxide was prepared under ultra-high vacuum conditions. ${ }^{39}$ Here, the thin layer of the adventitious carbon present on top of the $\mathrm{CuO}$ conceals the states near the Fermi level. The ionization energy of the $\mathrm{CuO}$ was found to be $5.7 \mathrm{eV}$, which is calculated by adding the work function and valence band maximum values.

Fig. 2c shows that the transparency of both ITO/PEDOT:PSS/ $\mathrm{CH}_{3} \mathrm{NH}_{3} \mathrm{PbI}_{3}$ and ITO/CuO NPs/ $\mathrm{CH}_{3} \mathrm{NH}_{3} \mathrm{PbI}_{3}$ electrodes is above $80 \%$ in all the visible spectra $(400-800 \mathrm{~nm})$. This guarantees that many photons reach the $\mathrm{CH}_{3} \mathrm{NH}_{3} \mathrm{PbI}_{3}$ photoactive layer. Importantly, the absorbance spectra of identically fabricated $\mathrm{CH}_{3} \mathrm{NH}_{3} \mathrm{PbI}_{3}$ photoactive layers on top of the two bottom electrodes are significantly different. The absorbance of $\mathrm{CH}_{3} \mathrm{NH}_{3}$ $\mathrm{PbI}_{3}$ on top of $\mathrm{CuO}$ NPs is stronger compared with that of $\mathrm{CH}_{3} \mathrm{NH}_{3} \mathrm{PbI}_{3}$ fabricated on top of PEDOT:PSS, in the whole range of wavelengths $(300-500 \mathrm{~nm})$ studied. The high transparency of the ITO/CuO NP bottom electrode as well as the improved absorption characteristics of the perovskite photoactive layer fabricated on top of it, as we shall show below, is of
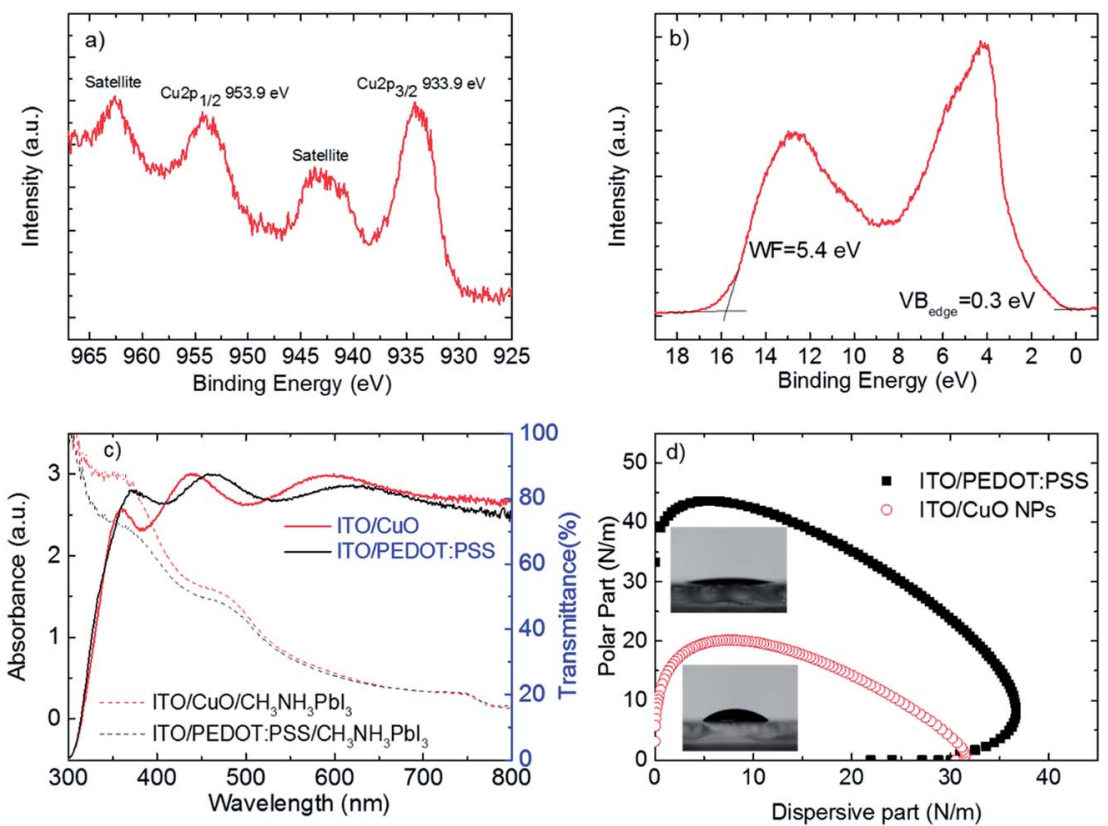

Fig. 2 (a) The XPS spectrum of the Cu 2p peak, (b) UPS spectrum of ITO/CuO substrates, (c) absorbance spectra of ITO/PEDOT:PSS/CH $\mathrm{NHH}_{3} \mathrm{Pbl}_{3}$ (black dashed line) and ITO/CuO NPs/ $\mathrm{CH}_{3} \mathrm{NH}_{3} \mathrm{Pbl}$ (red dashed line) electrodes. Transmittance spectra (right axis) of ITO/PEDOT:PSS (black solid line) and ITO/CUO NPs (red solid line), (d) surface energy wetting envelopes of ITO/PEDOT:PSS (black filled squares) and ITO/CuO NPs (red open circles). The insets represent digital photographs of a water drop on top of the corresponding layers. 
great importance for the performance of the corresponding photovoltaic devices.

Another important requirement for the bottom electrode of perovskite solar cells is its surface wetting properties. Fig. $2 \mathrm{~b}$ shows the surface free energy of the two bottom electrodes under study. Surface energy wetting envelopes are closed curves that are obtained when the polar fraction of a solid is plotted against the disperse part. ${ }^{40}$ With the help of the wetting envelope and knowledge of the polar and disperse parts of the surface energy (SFE) of a solid it is possible to predict whether a liquid whose surface tension components lies within this enclosed area will wet the corresponding solid. As shown in Fig. 2b, the calculated surface tension of the $\mathrm{CH}_{3} \mathrm{NH}_{3} \mathrm{PbI}_{3}$ precursor solution lies well inside the surface energy wetting envelope of the ITO/CuO bottom electrode and thus a good wetting is guaranteed. In addition, it is observed that the ITO/ CuO NP film exhibits a smaller size of the surface wetting envelope than the ITO/PEDOT:PSS thin film, which implies more hydrophobic character. The increase in hydrophobicity of the bottom electrode, could lead in increased grain size of the perovskite photoactive layers, which are fabricated on top, as suggested by C. Bi et. al. ${ }^{16}$

To verify the surface topography of the $\mathrm{CH}_{3} \mathrm{NH}_{3} \mathrm{PbI}_{3}$ photoactive layers fabricated identically on top of ITO/PEDOT:PSS and ITO/CuO NPs thin films, the as-obtained devices were analyzed by AFM measurements which are demonstrated in Fig. 3 together with the steady state photoluminescence (PL) measurements.

Fig. 3a shows the steady state $\mathrm{PL}$ spectra of $\mathrm{CH}_{3} \mathrm{NH}_{3} \mathrm{PbI}_{3}$ fabricated on top of glass and on top of $\mathrm{ITO} / \mathrm{CuO}$ or ITO/ PEDOT:PSS. The PL spectrum of $\mathrm{CH}_{3} \mathrm{NH}_{3} \mathrm{PbI}_{3}$ fabricated on top of glass shows a strong peak at $764 \mathrm{~nm}$. This strong signal is completely quenched when the $\mathrm{CH}_{3} \mathrm{NH}_{3} \mathrm{PbI}_{3}$ layer is fabricated on ITO/CuO as well as ITO/PEDOT:PSS with only a few counts measured representing nearly $100 \%$ PL quenching. The $100 \%$ $\mathrm{PL}$ quenching of the main $\mathrm{CH}_{3} \mathrm{NH}_{3} \mathrm{PbI}_{3} \mathrm{PL}$ peak at $764 \mathrm{~nm}$ clearly demonstrates excellent ITO/CuO bottom electrode operation.

Fig. 3b demonstrates the surface topography of $\mathrm{CH}_{3} \mathrm{NH}_{3} \mathrm{PbI}_{3}$ fabricated on top of ITO/PEDOT:PSS electrodes. It is observed that the $\mathrm{CH}_{3} \mathrm{NH}_{3} \mathrm{PbI}_{3}$ film is quite compact and relatively smooth $\left(R_{\mathrm{a}}=12.2 \mathrm{~nm}\right)$. However, the grain size of this film is very small and falls within the range of $\sim 100 \mathrm{~nm}$. Importantly, an impressive increase of $\mathrm{CH}_{3} \mathrm{NH}_{3} \mathrm{PbI}_{3}$ grain size is observed (Fig. 3c) when fabricated on top of ITO/CuO NPs. In this case, an average grain size of $\sim 500 \mathrm{~nm}$ is observed and the film maintains its compactness with a surface roughness $R_{\mathrm{a}} \sim 18 \mathrm{~nm}$. The impressive increase of the perovskite grain size when fabricated on top of CuO NPs could be partially attributed to the increased hydrophobicity of CuO NPs compared with PEDOT:PSS (Fig. 2b). Indeed, this observation is supported by the results obtained from the optical absorbance measurements (Fig. 2a). The increased absorbance of the perovskite photoactive layer on ITO/CuO NPs is a result of the increased perovskite grain size, which leads to an increased surface coverage and stronger absorption form the $\mathrm{CH}_{3} \mathrm{NH}_{3} \mathrm{PbI}_{3}$ crystals.

So far, we have analyzed the nature of the synthesized NPs and showed that the corresponding thin films fulfill a lot of requirements for serving as an efficient bottom electrode in $\mathrm{p}-\mathrm{i}-$ $\mathrm{n}$ perovskite solar cells. Therefore, $\mathrm{p}-\mathrm{i}-\mathrm{n}$ devices comprised of $\mathrm{ITO} / \mathrm{CuO} \quad \mathrm{NPs} / \mathrm{CH}_{3} \mathrm{NH}_{3} \mathrm{PbI}_{3} / \mathrm{PC}[70] \mathrm{BM} / \mathrm{AZO} / \mathrm{Al} \quad$ (CuO-device) were fabricated and compared with ITO/PEDOT:PSS/ $\mathrm{CH}_{3} \mathrm{NH}_{3}$ $\mathrm{PbI}_{3} / \mathrm{PC}[70] \mathrm{BM} / \mathrm{AZO} / \mathrm{Al}$ (PEDOT:PSS-device). Fig. 4 shows the photovoltaic operation of the best $\mathrm{p}-\mathrm{i}-\mathrm{n}$ devices under study using current-voltage plots $(J-V)$ and external quantum efficiency (EQE). The results are presented in Fig. 4 and were verified in several other identically executed experimental runs.

Fig. 4 a shows the $J-V$ plots under illumination for the best $\mathrm{p}-$ i-n devices under study. Both CuO-based and PEDOT:PSS-based devices exhibited good diode behavior with high fill factor (FF), open-circuit voltage $\left(V_{\mathrm{oc}}\right)$ and short circuit current density $\left(J_{\mathrm{sc}}\right)$ values. It is worth mentioning that both $\mathrm{p}-\mathrm{i}-\mathrm{n}$ devices show negligible hysteresis between the two-different scan $J-V$ directions (Fig. S7†). Importantly, the photovoltaic performance of the CuO-based perovskite solar cell presented is stable for more than 30 minutes under continuous 1 sun illumination (Fig. S8 $\dagger$ ), indicating no photo-chemical interaction between $\mathrm{CuO} \mathrm{HTL}$ and $\mathrm{CH}_{3} \mathrm{NH}_{3} \mathrm{PbI}_{3}$. The PEDOT:PSS-based device exhibited $V_{\mathrm{oc}}=0.9 \mathrm{~V}, J_{\mathrm{sc}}=15.7 \mathrm{~mA} \mathrm{~cm}^{-2}, \mathrm{FF}=75 \%$ and $\mathrm{PCE}=$ $10.6 \%$. Importantly, the CuO NP-based inverted device exhibited $V_{\mathrm{oc}}=1.09 \mathrm{~V}$, which is $0.19 \mathrm{~V}$ higher compared to that of the PEDOT:PSS-based device $\left(J_{\mathrm{sc}}=18.2 \mathrm{~mA} \mathrm{~cm}^{-2}, \mathrm{FF}=77 \%\right.$ and PCE $=15.3 \%$ ). In addition to the best device performance presented in Fig. 4, CuO-based $\mathrm{p}-\mathrm{i}-\mathrm{n}$ perovskite solar cells
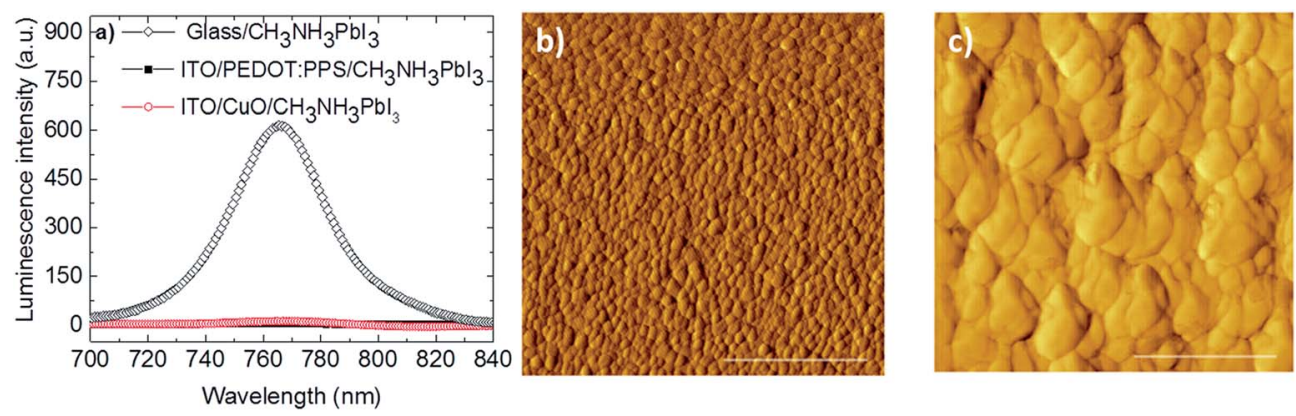

Fig. 3 (a) Photoluminescence spectra of glass $/ \mathrm{CH}_{3} \mathrm{NH}_{3} \mathrm{Pbl}_{3}$ (black open diamonds), ITO/PEDOT:PSS/CH $\mathrm{NH}_{3} \mathrm{~Pb}{ }_{3}$ (black filled squares), and ITO/CuO/ $\mathrm{CH}_{3} \mathrm{NH}_{3} \mathrm{Pbl}_{3}$ (red open circles). AFM measurements of (b) ITO/PEDOT:PSS/ $\mathrm{CH}_{3} \mathrm{NH}_{3} \mathrm{Pbl}_{3}$ and (c) ITO/CuO/CH $\mathrm{NH}_{3} \mathrm{Pbl}$. The scale bar is $2 \mu \mathrm{m}$. 

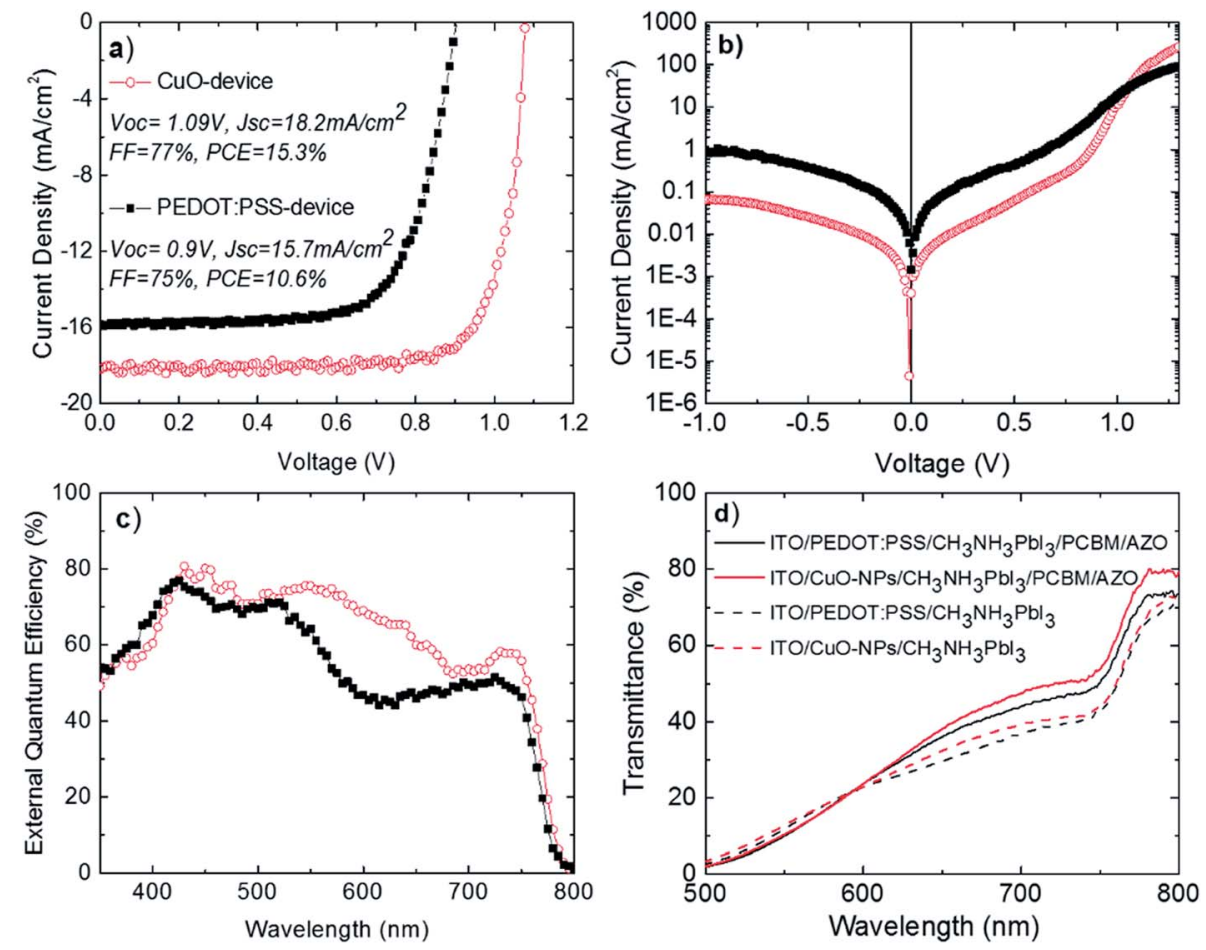

Fig. 4 Current density-voltage ( $J-V$ characteristics (a) under illumination, (b) under dark conditions, (c) EQE spectra of the two $p-i-n$ devices under this study ITO/PEDOT:PSS/CH $\mathrm{NH}_{3} \mathrm{Pbl}_{3} / \mathrm{PC}$ [70]BM/AZO/Al (black filled squares) and ITO/CuO NPs/CH $3 \mathrm{NH}_{3} \mathrm{~Pb}{ }_{3} / \mathrm{PC}[70] \mathrm{BM} / \mathrm{AZO} / \mathrm{Al}$ (OPpen red circles) and (d) transmittance measurements of different layer stacks comprising the $\mathrm{p}-\mathrm{i}-\mathrm{n}$ solar cells under study.

exhibit significant average device performance improvement compared with PEDOT:PSS-based devices and good performance reproducibility as shown in statistical analysis in Fig. S9. $\dagger$ As predicted before, we ascribe the enhanced $V_{\text {oc }}$ to the higher work function of $\mathrm{CuO}(5.4 \mathrm{eV}$, Fig. $2 \mathrm{~b})$, than that of PEDOT:PSS $(5 \mathrm{eV}){ }^{15}$ The latter leads to increased built-involtage $\left(V_{\mathrm{bi}}\right)$ as predicted by the $\mathrm{p}-\mathrm{i}-\mathrm{n}$ model and thus increased $V_{\mathrm{oc}}$. The higher work function is most possibly responsible for the increased $J_{\mathrm{sc}}$ and $\mathrm{FF}$ for the CuO-device by providing better energetic steps and thus reducing energetic barriers for unimpeded hole collection for the bottom electrode. In addition, the increased $\mathrm{CH}_{3} \mathrm{NH}_{3} \mathrm{PbI}_{3}$ grain size when fabricated on top of CuO NPs compared to those fabricated on top of PEDOT:PSS (Fig. $3 \mathrm{~b}$ and c) could also have a beneficial effect on the increased photovoltaic parameters of the CuO-based device. The increased grain size of the $\mathrm{CH}_{3} \mathrm{NH}_{3} \mathrm{PbI}_{3}$ photoactive layer would lead to a reduced grain boundary area and thus reduced non-geminate recombination probability, which is a parasitic process dominating at the grain boundaries and limiting the $V_{\mathrm{oc}}$ and $J_{\mathrm{sc}}$ values of perovskite solar cells. ${ }^{41}$

The above described mechanisms are further verified by Fig. 4b. The CuO-NP based device exhibits a very good diode operation. Importantly, the leakage current (at voltage equal to $-1 \mathrm{~V}$ ) for the CuO NP based device is 1 order of magnitude lower compared with the PEDOT:PSS based device. In addition, the value of series resistance for the CuO-based device has been calculated (by using the slope of the dark curve after $1.1 \mathrm{~V}$ ) at $R_{\mathrm{s}}$ $=1.82 \mathrm{ohm}$ which is lower from the one calculated for the PEDOT:PSS-based device at $3.12 \mathrm{ohm}$. The above measurements show that the implementation of CuO-NPs HTLs significantly suppresses the parasitic resistances within the solar cell. These observations provide additional experimental evidence for the high hole-extraction ability of the proposed CuO-NP HTLs for perovskite solar cells.

Fig. $4 c$ shows the external quantum efficiency (EQE) as a function of wavelength for the two $\mathrm{p}-\mathrm{i}-\mathrm{n}$ devices under study. In accordance with Fig. 4a, the CuO NP-based device exhibited higher EQE in almost the whole spectral range (400-800 nm) compared to the PEDOT:PSS-based device. The integrated $J_{\mathrm{sc}}$ values extracted from the EQE spectra of the two devices demonstrate a good match with the measured $J_{\mathrm{sc}}$ from the $J-V$ characteristics, with an $\sim 5 \%$ and $\sim 3 \%$ deviation for the PEDOT:PSS-based and the $\mathrm{CuO}$ NP-based devices, respectively. Despite the similar shape in the EQE spectra for both devices under study before $530 \mathrm{~nm}$, the EQE spectra of the PEDOT:PSS-based device exhibit a significantly sharper drop compared with the EQE spectra of the CuO NP-based device in the range of 530-630 nm. This observation could be partially explained by the higher transmittance of the CuO NP electrodes in this region (Fig. 2a).

Fig. 4c shows the transmittance measurements of $\mathrm{ITO} / \mathrm{CuO}$ or PEDOT:PSS $/ \mathrm{CH}_{3} \mathrm{NH}_{3} \mathrm{PbI}_{3}$ as well as of the full stacks under comparison ITO/CuO or PEDOT:PSS/ $\mathrm{CH}_{3} \mathrm{NH}_{3} \mathrm{PbI}_{3} / \mathrm{PCBM} / \mathrm{AZO}$ without the $\mathrm{Al}$ back contact of the device (Fig. 4c). Importantly the transmittance of CuO-NPs/ $\mathrm{CH}_{3} \mathrm{NH}_{3} \mathrm{PbI}_{3}$ is higher compared with the transmittance PEDOT:PSS $/ \mathrm{CH}_{3} \mathrm{NH}_{3} \mathrm{PbI}_{3}$ after $600 \mathrm{~nm}$. The CuO-NP based full layer stacks also show higher transmittance beyond the 600-800 $\mathrm{nm}$ range compared with PEDOT:PSS-based layer stacks. It is likely that the transmittance 
enhancement above $600 \mathrm{~nm}$ originates from CuO-NP light scattering effects. We have recently shown that higher $\mathrm{EQE}$ is observed in the region of 550-760 nm when aluminum-doped zinc oxide nanoparticulate electron selective contacts are used within the n-part of the $\mathrm{p}-\mathrm{i}-\mathrm{n}$ perovskite PV structure, resulting in light scattering effects and increased back electrode reflectivity. ${ }^{7}$ We propose that $\mathrm{CuO}$ nanoparticulate hole selective contacts further contribute to light scattering phenomena within the $\mathrm{p}-\mathrm{i}-\mathrm{n}$ perovskite PV structure. Thus, the higher EQE observed in the region of 550-800 $\mathrm{nm}$ for the perovskite solar cells incorporating $\mathrm{CuO}$ nanoparticulate hole selective contacts is attributed to additional scattered light from CuO NPs that result in increased reflective light of $\mathrm{Al}$ and, therefore, improved absorption properties of the corresponding perovskite active layer.

\section{Conclusions}

We have demonstrated a novel solvothermal synthetic route for the development of room temperature solution processed nanoparticulate interfacial layers for highly efficient $\mathrm{p}-\mathrm{i}-\mathrm{n}$ perovskite solar cells. The CuO NPs and thin films are synthesized using thermal decomposition of $\mathrm{CuCl}$ diluted in DMSO at low temperatures and short reaction times. The synthetic procedure results in high purity monodisperse, spherical $\mathrm{CuO}$ NPs with a monoclinic crystal structure and tunable sizes from 5 to $10 \mathrm{~nm}$ by simply changing the reaction temperature. The high quality CuO NP dispersions in DMSO were used to fabricate $\mathrm{CuO}$ hole selective contacts between ITO and perovskite active layers with a thickness of about $15 \mathrm{~nm}$ without any post deposition temperature treatment. The use of $\mathrm{CuO}$ NPs as an interfacial layer between ITO and the $\mathrm{CH}_{3} \mathrm{NH}_{3} \mathrm{PbI}_{3}$ active layer leads to an increased $V_{\text {oc }}$ of $1.09 \mathrm{~V}$ and a PCE of $15.3 \%$, compared to that achieved with the PEDOT:PSS-hole selective contact based $\mathrm{CH}_{3} \mathrm{NH}_{3} \mathrm{PbI}_{3}$ solar cell device, which exhibits a $V_{\text {oc }}$ of 0.9 and PCE up to $10.6 \%$. The improved device performance arises from the bottom electrode CuO NP-based interface modification. The quality of the proposed ITO/CuO-NP bottom electrode is indicated by XPS/UPS measurements and the efficient quenching of the photoluminescence of $\mathrm{CH}_{3} \mathrm{NH}_{3}$ $\mathrm{PbI}_{3}$ films. In addition, the $\mathrm{CH}_{3} \mathrm{NH}_{3} \mathrm{PbI}_{3}$ photoactive layer when fabricated on top of ITO/CuO NPs shows improved crystallinity and absorption characteristics which also contribute to the overall increase in device performance. Furthermore, improved light manipulation within the $\mathrm{p}-\mathrm{i}-\mathrm{n} \mathrm{CH}_{3} \mathrm{NH}_{3} \mathrm{PbI}_{3}$ solar cell is also observed due to the nanoparticulate nature of the $\mathrm{CuO}$ interfacial layer. The above experimental observations suggest that nanoparticulate based interface modification provides a series of benefits in $\mathrm{p}-\mathrm{i}-\mathrm{n}$ perovskite solar cell operation. The solvothermal synthetic route proposed in this work could potentially be used for the preparation of other low temperature solution processed nanoparticulate metal oxide thin films suitable for flexible perovskite solar cells and other printing electronic applications.

\section{Conflicts of interest}

There are no conflicts of interest to declare.

\section{Acknowledgements}

This project has received funding from the European Research Council (ERC) under the European Union's Horizon 2020 research and innovation programme (grant agreement No. 647311).

\section{Notes and references}

1 Y. Zhao and K. Zhu, Chem. Soc. Rev., 2016, 45, 655.

2 S. Yakunin, M. Sytnyk, D. Kriegner, S. Shrestha, M. Richter, G. J. Matt, H. Azimi, C. J. Brabec, J. Stangl, M. V. Kovalenko and W. Heiss, Nat. Photonics, 2015, 9, 444. 3 NREL Chart.

4 M. Saliba, T. Matsui, J.-Y. Seo, K. Domanski, J.-P. CorreaBaena, M. K. Nazeeruddin, S. M. Zakeeruddin, W. Tress, A. Abate, A. Hagfeldt and M. Grätzel, Energy Environ. Sci., 2016, 9, 1989.

5 A. Kojima, K. Teshima, Y. Shirai and T. Miyasaka, J. Am. Chem. Soc., 2009, 131, 6050.

6 H.-S. Kim, C.-R. Lee, J.-H. Im, K.-B. Lee, T. Moehl, A. Marchioro, S.-J. Moon, R. Humphry-Baker, J.-H. Yum, J. E. Moser, M. Grätzel and N.-G. Park, Sci. Rep., 2012, 2, 59.

7 P. Docampo, J. M. Ball, M. Darwich, G. E. Eperon and H. J. Snaith, Nat. Commun., 2013, 4, 2761.

8 A. Savva, I. Burgués-Ceballos and S. A. Choulis, Adv. Energy Mater., 2016, 1600285.

9 Y. Shao, Z. Xiao, C. Bi, Y. Yuan and J. Huang, Nat. Commun., 2014, 5, 5784.

10 W. Shockley and H. J. Queisser, J. Appl. Phys., 1961, 32, 510. 11 W. Nie, H. Tsai, R. Asadpour, J.-C. Blancon, A. J. Neukirch, G. Gupta, J. J. Crochet, M. Chhowalla, S. Tretiak, M. A. Alam, H.-L. Wang and A. D. Mohite, Science, 2015, 347, 522.

12 M. Gratzel, Nat. Mater., 2014, 13, 838.

13 A. Savva, M. Neophytou, C. Koutsides, K. Kalli and S. A. Choulis, Org. Electron., 2013, 14, 3123.

14 J. H. Kim, P. W. Liang, S. T. Williams, N. Cho, C. C. Chueh, M. S. Glaz, D. S. Ginger and A. K. Jen, Adv. Mater., 2015, 27, 695.

15 A. Savva, E. Georgiou, G. Papazoglou, A. Z. Chrusou, K. Kapnisis and S. A. Choulis, Sol. Energy Mater. Sol. Cells, 2015, 132, 507.

16 C. Bi, Q. Wang, Y. Shao, Y. Yuan, Z. Xiao and J. Huang, Nat. Commun., 2015, 6, 7747.

17 J. You, L. Meng, T.-B. Song, T.-F. Guo, Y. Yang, W.-H. Chang, Z. Hong, H. Chen, H. Zhou, Q. Chen, Y. Liu, N. De Marco and Y. Yang, Nat. Nanotechnol., 2016, 11, 75.

18 J. W. Jung, C.-C. Chueh and A. K. Y. Jen, Adv. Mater., 2015, 27, 7874.

19 K. Zhao, R. Munir, B. Yan, Y. Yang, T. Kim and A. Amassian, J. Mater. Chem. A, 2015, 3, 20554.

20 A. Savva and S. A. Choulis, Appl. Phys. Lett., 2013, 102, 233301.

21 J. H. Kim, P.-W. Liang, S. T. Williams, N. Cho, C.-C. Chueh, M. S. Glaz, D. S. Ginger and A. K. Y. Jen, Adv. Mater., 2015, 27, 695. 
22 Z. Zhu, Y. Bai, X. Liu, C.-C. Chueh, S. Yang and A. K.-Y. Jen, Adv. Mater., 2016, 28, 6478.

23 X. Liang, S. Bai, X. Wang, X. Dai, F. Gao, B. Sun, Z. Ning, Z. Ye and Y. Jin, Chem. Soc. Rev., 2017, 46, 1730.

24 U. Kwon, B.-G. Kim, D. C. Nguyen, J.-H. Park, N. Y. Ha, S.-J. Kim, S. H. Ko, S. Lee, D. Lee and H. J. Park, Sci. Rep., 2016, 6, 30759.

25 H. Zhang, J. Cheng, F. Lin, H. He, J. Mao, K. S. Wong, A. K. Y. Jen and W. C. H. Choy, ACS Nano, 2016, 10, 1503.

26 P. Vivo, A. Ojanperä, J.-H. Smått, S. Sandén, S. G. Hashmi, K. Kaunisto, P. Ihalainen, M. T. Masood, R. Österbacka, P. D. Lund and H. Lemmetyinen, Org. Electron., 2017, 41, 287.

27 S. S. Shin, W. S. Yang, E. J. Yeom, S. J. Lee, N. J. Jeon, Y.-C. Joo, I. J. Park, J. H. Noh and S. I. Seok, J. Phys. Chem. Lett., 2016, 7, 1845.

28 L. Liu, T. Matsushita, P. Concepción, A. Leyva-Pérez and A. Corma, ACS Catal., 2016, 6, 2211.

29 I. Tamiolakis, I. T. Papadas, K. C. Spyridopoulos and G. S. Armatas, RSC Adv., 2016, 6, 54848.

30 V. Markoulaki I, I. Papadas, I. Kornarakis and G. Armatas, Nanomaterials, 2015, 5, 1971.

31 F. Wang, H. Li, Z. Yuan, Y. Sun, F. Chang, H. Deng, L. Xie and H. Li, RSC Adv., 2016, 6, 79343.
32 M. I. Hossain, F. H. Alharbi and N. Tabet, Sol. Energy, 2015, 120, 370 .

33 C. Zuo and L. Ding, Small, 2015, 11, 5528.

34 W. Sun, Y. Li, S. Ye, H. Rao, W. Yan, H. Peng, Y. Li, Z. Liu, S. Wang, Z. Chen, L. Xiao, Z. Bian and C. Huang, Nanoscale, 2016, 8, 10806.

35 H. Rao, S. Ye, W. Sun, W. Yan, Y. Li, H. Peng, Z. Liu, Z. Bian, Y. Li and C. Huang, Nano Energy, 2016, 27, 51.

36 J. Ghijsen, L. H. Tjeng, J. van Elp, H. Eskes, J. Westerink, G. A. Sawatzky and M. T. Czyzyk, Phys. Rev. B: Condens. Matter Mater. Phys., 1988, 38, 11322-11330.

37 D. Tahir and S. Tougaard, J. Phys.: Condens. Matter, 2012, 24, 17.

38 C. Benndorf, H. Caus, B. Egert, H. Seidel and F. Thieme, J. Electron Spectrosc. Relat. Phenom., 1980, 19, 77.

39 M. T. Greiner, M. G. Helander, W.-M. Tang, Z.-B. Wang, J. Qiu and Z.-H. Lu, Nat. Mater., 2011, 11, 76.

40 A. Savva, F. Petraki, P. Elefteriou, L. Sygellou, M. Voigt, M. Giannouli, S. Kennou, J. Nelson, D. D. C. Bradley, C. J. Brabec and S. A. Choulis, Adv. Energy Mater., 2013, 3, 391.

41 D.-Y. Son, J.-W. Lee, Y. J. Choi, I.-H. Jang, S. Lee, P. J. Yoo, H. Shin, N. Ahn, M. Choi, D. Kim and N.-G. Park, Nat. Energy, 2016, 1, 16081. 